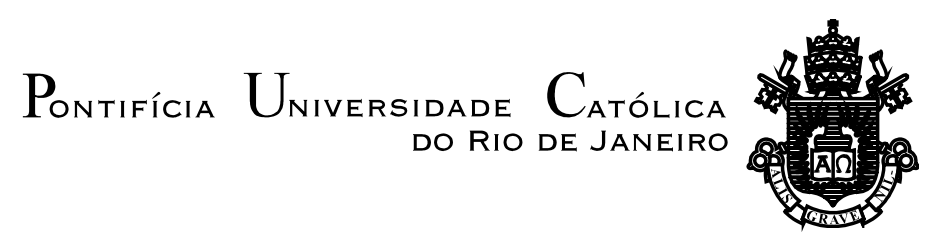

Caio Rangel Praes

Two Essays on Liquidity and Strategic Interaction

Dissertação de Mestrado

Thesis presented to the Postgraduate Program in Economics of the Departamento de Economia, PUCRio, as partial fulfillment for the degree of Mestre em Economia.

Advisor: Prof. Vinicius Carrasco

Rio de Janeiro

March 2015 


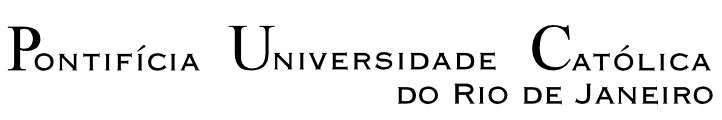

Caio Rangel Praes

\section{Two Essays on Liquidity and Strategic Interaction}

Thesis presented to the Postgraduate Program in Economics of the Departamento de Economia, PUC-Rio, as partial fulfillment for the degree of Mestre em Economia. Approved by the following commission.

Prof. Vinicius Carrasco

Advisor

Departamento de Economia - PUC-Rio

Prof. Leonardo Rezende

Departamento de Economia - PUC-Rio

Prof. Pablo Salgado

Opus Gestão de Recursos

Monica Herz

Coordinator of the Centro de Ciências Sociais - PUC-Rio

Rio de Janeiro, 20th March 2015 
All rights reserved

\section{Caio Rangel Praes}

Undergraduate in Economics from Pontifícia Universidade Católica do Rio de Janeiro in 2011.

Bibliographic data

Caio Rangel Praes

Two Essays on Liquidity and Strategic Interaction/ Caio Praes Rangel; advisor: Vinicius Carrasco - 2015

31f. : il.; $30 \mathrm{~cm}$

Dissertação (Mestrado em Economia)-Pontifícia Universidade Católica do Rio de Janeiro, Rio de Janeiro, 2015.

Incluí referências bibliográficas.

1. Economia - Teses. 2.Barganha 3. Informação incompleta 4. Prazo I. Carrasco, Vinicius. II. Pontifícia Universidade Católica do Rio de Janeiro. Departamento de Economia. IV. Título

CDD:330 


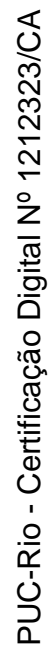

Esta dissertação é dedicada a minha família. 


\section{Agradecimentos}

I give thanks to my advisor, Professor Vinicius Carrasco, for providing the needed stimuli to complete this piece.

I acknowledge the professional of ethics my colleagues, a yardstick I will carry for the rest of my life.

I express gratitude towards the members of the committee, whose advice was invaluable yet pleasant to hear.

I would also like to record my gratitude towards every professor and employee I have had the pleasure to interact during my time at PUC-Rio.

Last, but not least, I wish to remember the financial support Capes bestowed upon me. 


\section{Resumo}

Caio Rangel Praes; Carrasco, Vinicius(orientador). Dois Ensaios sobre Liquidez e Interação Estratégica. Rio de Janeiro, 2015. 31p. Dissertação de Mestrado - Departamento de Economia, Pontifícia Universidade Católica do Rio de Janeiro.

Nessa dissertação de mestrado são desenvolvidos dois ensaios nos quais modelos clássicos de interação estratégica são expandidos para investigar relações entre liquidez e informação assimétrica. No primeiro ensaio, o objetivo é investigar a negociação de opções ilíquidas sujeitas a incerteza exógena. Em particular, desenvolve-se um modelo de barganha no qual a incerteza exógena subjacente é melhor prevista pelo comprador e mostra-se que a existência de uma opção de fora para o vendedor permite que este fixe um prazo para o fim da negociação, estratégia que se mostra ser parte do equilíbrio do jogo. Em outras palavras, o vendedor escolhe uma data para exercer sua opção de fora, o que acontece se não houver acordo até esta data. No segundo ensaio, o objetivo é investigar como corridas bancárias do lado do ativo se relacionam a uma fonte externa de liquidez na forma de um mercado secundário de empréstimos bancários. O principal resultado do segundo ensaio é que corridas bancárias no lado do ativo podem contribuir para existência do mercado secundário de empréstimos bancários, pois criam incentivos para a venda de empréstimos bancários, independentemente de informações privadas que o vendedor venha a adquirir. Esse resultado pode ser relevante no contexto de bancos de varejo.

\section{Palavras-chave}

barganha; informação incompleta; prazo; verificação custosa de estado; inadimplência coordenada; venda de empréstimos 


\section{Abstract}

Caio Rangel Praes; Carrasco, Vinicius(advisor). Two Essays on Liquidity and Strategic Interaction. Rio de Janeiro, 2015. 31p. Dissertação de Mestrado - Departamento de Economia, Pontifícia Universidade Católica do Rio de Janeiro.

In this master's degree thesis, I present two essays based on classic models of strategic interaction. In both essays, the overarching theme is how liquidity relates to asymmetric information. On the first, the aim is to investigate bargaining over an illiquid option subject to exogenous uncertainty. In particular, I develop a bargaining model in which the underlying uncertainty is better predicted by the buyer and establish that the existence of the seller's exercise option allows "deadline strategies" that are shown to be part of the equilibrium of such game. In other words, the seller fixes a date to exercise her outside option, provided that the trade does not take place until that time. On the second essay, I seek to investigate how borrower runs relate to external funding thorough a market for bank loans. This essay's conclusion is that borrower runs may be a driver of the originate-todistribute banking business model, for it induces the sale of loans irrespective of their quality, rendering the market for bank loans information insensitive. This result might be relevant in the context of relationship banking.

\section{Keywords}

bargaining; incomplete information; deadline; costly state verification; coordinated default; loan sales 


\section{Sumário}

1 A Reason Bargaining Ends $\quad 10$

$\begin{array}{ll}\text { 1.1. Introduction } & 10\end{array}$

1.2. Related Literature 11

1.3. The Model 12

1.4. Stationary Equilibrium 15

1.5. Deadline Strategy 16

$\begin{array}{ll}\text { 1.6. Conclusion } & 17\end{array}$

2 A Reason The Secondary Market for Bank Loans Exists 18

$\begin{array}{ll}\text { 2.1. Introduction } & 18\end{array}$

2.2. Related Literature 19

2.3. The Model 20

2.4. Conclusion 23

3 References $\quad 24$

4 Appendix 26

4.1. First Essay 26

4.2. Second Essay 30 
"We have not succeed in answering all our problems. The answers we have found only serve to raise a whole set of new questions. In some ways, we feel confused as ever, but we believe we are confused on a higher level and about more important things." 


\section{A Reason Bargaining Ends}

\subsection{Introduction}

Not every asset has a liquid market, for many are both severely limited in supply and very hard to put a price on. The dealing of such assets usually occurs through bilateral bargaining, and private negotiation among sophisticated traders is arguably the norm. In the model presented in this paper, the asset over which the bargaining takes place is an option whose value can only be determined with certainty after its exercise. However, one of the players has more information about the underlying stochastic process. As this kind of information need not be inherent to the asset, there is no compelling reason why the better informed player should always be the seller.

Consider, for instance, the trading of mineral rights. A big mining/oil company may be more knowledgeable in estimating the costs of the development of the project than the owner of the rights, who may be financially sophisticated but lacking geological/technical expertise. In the M\&A jargon, such buyer would be called "strategic" (as opposed to "financial"). However, the framework developed in this paper can be applied to general circumstances. In particular, the exit from any bargaining in a changing environment can be characterized as an option, a fact not fully explored in the literature.

If a model ignores the possibility of an exit, it deliberately assumes that an agreement is bound to happen at some point. Such framework might be appropriate for certain cases, such as the negotiations between a firm and its employees, but that is not suited to negotiations in general. According to the Bloomberg Businessweek list of biggest failed merger talks ${ }^{1}$, strategic exit of a negotiating player is the single most important reason for failure (followed by absence of regulatory approval and accounting fraud). Likewise, a model that features non-agreement in an exogenous fashion or in a symmetric information setting will fail to reach the implication this paper argues as novel.

\footnotetext{
${ }^{1}$ http://images.businessweek.com/ss/09/04/0407_failed_merger_talks/1.htm
} 
This paper argues that in certain circumstances of incomplete information, the stationary equilibrium of a bargaining game is a deadline, i.e. the seller will always find it optimal to exercise the option if no agreement is reached by a certain time. Such result connects two strains of the bargaining literature namely bargaining with incomplete information and bargaining with deadlines. Note that a self-imposed deadline is a possible equilibrium only when the action set incorporates irrevocable non-agreement.

\subsection{Related Literature}

Following the structure laid by Rubinstein (1982) (i.e. the bargaining as a dynamic process of bilateral negotiation), the bargaining literature has evolved in many directions. Fundenberg, Levine and Tirole (1985), Deneckere and Liang (2006) and many others (see Asubel, Cramton and Deneckere, 2002) explored how agents' incomplete information affects such structure. Fundenberg, Levine and Tirole (1987) considered an asset that carries an outside option to the seller. Avery and Zemsky (1994), Merlo and Wilson (1995, 1998), and Fuchs and Skrypacz (2010) attached stochastic processes to the asset.

The model Fundenberg, Levine and Tirole (1987) develop is close in spirit to what I seek to investigate in this paper. In their model, the seller can either consume the good herself (i.e. exercise the option) or switch to a different buyer. However, the value of the good does not change with time, only the belief the seller builds based on the behavior of the buyers. Besides, the switching of buyers limits the extent of strategic interaction, which is thought to be pervasive in illiquid markets (see Dang, Gorton and Holmstrom, 2009).

Avery and Zemsky (1994) addressed what was left unexplored in Fundenberg, Levine and Tirole (1987), i.e. the strategic interaction considered does contemplate option value arising from intrinsic characteristics of the asset. What they left out is the incomplete information setting. The model Fuchs and Skrypacz (2010) developed has those features, but the only way the option can be exercised is through an exogenous event.

The main point of this paper is that the conjunction of all such features (i.e. incomplete information, time-varying intrinsic value and an outside option in the action set) in a single model provides a rationale for self-imposed deadlines, an 
occurrence possibly absent in the bargaining literature, but arguably prevalent in real-life.

Fershtman and Seidmann (1993) present a bargaining game that exhibits delayed settlements. However, the deadline is imposed by the structure of the model, i.e. there is no surplus to be divided after a certain deadline. Besides, their model's solution concept is nonstationary. Mauleon and Vannetelbosch (2004) analyze a similar structure, a two-stage game in which the deadline is agreed before the bargaining part. The result provided in this paper, however, establishes the deadline through the course of the game (i.e. nothing in the structure of the game imposes that the seller must commit herself to a termination date) and uses the standard solution concept of stationary equilibrium.

\subsection{The Model}

Consider a discrete time, two-person, bargaining model. The value of asset at period $t$ is governed by the underlying process $Z_{t}$, which is an i.i.d. random variable drawn every period. Specifically, $Z_{t}$ takes values $H$ or $L$, each with probability $1 / 2$. As in Hanazono and Watanabe (2012), there is a signal $s_{t}$ such that $\operatorname{Pr}\left(Z_{t}=L \mid s_{t}=l\right)=\operatorname{Pr}\left(Z_{t}=H \mid s_{t}=h\right)=\alpha \in(0.5,1)$. The signal is private to the buyer, whose valuations $f(Z t)+q$ are indexed by his type $q$, which is assumed to follow an uniform distribution.

Any informational advantage regarding $Z_{t}$ can only be relevant if it changes accordingly. The type $q$ conveys information that is fixed, thus, it is inadequate to ascribe informational advantage on $Z_{t}$. Therefore, the inclusion of the signal is a natural development for a model that aims to describe asymmetric information over the time-varying intrinsic value of the asset.

The timing is such that the buyer receives his private signal and then the seller proposes a deal. If the deal is rejected, the seller may either exercise her option or move to the next period. If a deal is reached at price $p$ the payoffs are $U_{s}=\left(\delta_{s}\right)^{t} p$ for the seller and $U_{b}=\left(\delta_{b}\right)^{t}\left(f\left(Z_{t}\right)+q-p\right)$ for the buyer. If the seller decides to exercise her option, her payoff is $\left(\delta_{s}\right)^{t} Z_{t}$ instead.

The model lends itself to a dynamic programming approach. Following Fudenberg, Levine and Tirole (1985), who established the property that enables the use of dynamic programming in incomplete information bargaining, I will extend the validity of this property to this particular model. Given their result, the 
intuition of why the property holds is simple: it is as if we had parallel bargaining processes, one for each state of nature (signal).

Since I assumed a buyer's payoff to be linearly related to his type $q$, it was implicitly stated that the type $q$ describes the idiosyncratic preferences of a given buyer, i.e. the heterogeneity among buyers is not affected by the state of nature. This hypothesis is crucial to the following Lemma, which Fudenberg, Levine and Tirole (1985) called "Successive Skimming".

Lemma 1 Given the history $h_{n}$ of the game, if a buyer of type $q_{l}$ accepts the current offer when his private signal is $l$, then all types $q \geq q_{l}$ would have accepted the same offer in the same circumstances. Analogously, if a buyer of type $q_{h}$ accepts the current offer when his private signal is $h$, then all types $q \geq q_{h}$ would have accepted the same offer in the same circumstances. In other words, to every sequential equilibrium there is a non-increasing function $P\left(h_{n}, q_{l}, q_{h}\right)$ such that the vector $\left(q_{l}, q_{h}\right)$ provides the offer's cutoff points conditional on the two possible private signals.

Given that the seller does not observe the signal $s_{t}$, her beliefs must take into account the two possible outcomes of the signal, thus, they correspond to a bi-dimensional vector $\left(q_{l}^{0}, q_{h}^{0}\right)$. Let $G_{q_{l}, q_{h}}(\tau)$ denote the seller's belief associated with $\left(q_{l}, q_{h}\right)$ (i.e. the uniform distribution on $\left[0, q_{l}\right]$ or $\left[0, q_{h}\right]$, depending on the signal's putative realization). Let $g_{q_{l}, q_{h}}(\tau)$ denote the corresponding density.

Lemma 2 If the seller is assumed to update her beliefs following a rejection of her offer based on Bayes' formula and her initial priors are correct, then to every price trajectory there is a unique correspondence that connects the length of the game, i.e. the number of preceding rejections, to the bi-dimensional vector that denotes her belief.

In equilibrium, the seller correctly assesses the strategy of the buyer, so, in effect she chooses not the price, but the types. Let $W_{s}\left(q_{l}, q_{h}\right)$ denote the seller's maximized expected payoff when the state is $\left(q_{l}, q_{h}\right)$.

Proposition 1 The seller's trade-off is then captured by the following dynamic programming equation: 


$$
\begin{aligned}
& W_{s}\left(q_{l}, q_{h}\right) \\
& =q_{l}^{\prime} \leq q_{l}, q_{h}^{\prime} \leq q_{h}, \Upsilon_{t}\left(q_{l}, q_{h}\right) \in[0,1]\left\{E _ { x } \left[P ( q _ { l } ^ { \prime } , q _ { h } ^ { \prime } ) \left(0.5 \int_{q_{l}^{\prime}}^{x} g_{q_{l}, q_{h}}(\tau) d \tau\right.\right.\right. \\
& \left.+0.5 \int_{q_{h}^{\prime}}^{x} g_{q_{l}, q_{h}}(\tau) d \tau\right) \\
& +\left(\delta_{s} W_{s}\left(q_{l}^{+1}, q_{h}^{+1}\right) Y_{t}\left(q_{l}, q_{h}\right)+E\left[Z_{t} \mid R\right]\left(1-Y_{t}\left(q_{l}, q_{h}\right)\right)\right)(1 \\
& \left.\left.\left.-0.5 \int_{q_{l}^{\prime}}^{x} g_{q_{l}, q_{h}}(\tau) d \tau+0.5 \int_{q_{h}^{\prime}}^{x} g_{q_{l}, q_{h}}(\tau) d \tau\right)\right]\right\}
\end{aligned}
$$

where $Y_{t}\left(q_{l}, q_{h}\right)$ stands for the probability that the seller does not exercise her option following a rejection of $P\left(q_{l}^{\prime}, q_{h}^{\prime}\right)$, given her beliefs. The seller's belief is completely determined by the length of the game, her initial belief and her strategy. In other words, for a given trajectory of the price, her belief is a function of the number of rejections. Therefore, we can also express $Y_{t}\left(q_{l}, q_{h}\right)$ as a function of time, for the length of the game increases through rejections - the subscript $t$ is a reminder of this fact.

To understand the previous equation, observe that if the current state (type) is $\left(q_{l}, q_{h}\right)$ and the seller offers $P\left(q_{l}^{\prime}, q_{h}^{\prime}\right)$, then all buyer types in the interval $\left[q_{l}^{\prime}, q_{l}\right]$ accept if $s_{t}=l$ and, likewise, all buyer types in the interval $\left[q_{h}^{\prime}, q_{h}\right]$ accept if $s_{t}=h$. Conditional on the offer being accepted, the seller's payoff is $P\left(q_{l}^{\prime}, q_{h}^{\prime}\right)$; the likelihood of this happening is $\left(0.5 \int_{q_{l}^{\prime}}^{x} g_{q_{l}, q_{h}}(\tau) d \tau+0.5 \int_{q_{h}^{\prime}}^{x} g_{q_{l}, q_{h}}(\tau) d \tau\right)$. Rejection is the complement of acceptance and its probability is calculated as such. Rejection moves the state to $\left(q_{l}^{+1}, q_{h}^{+1}\right)$ and results in the seller having to decide either to settle for the expected payoff $W_{s}\left(q_{l}^{+1}, q_{h}^{+1}\right)$ with a one-period delay or exercise her option, whose payoff is $E\left[Z_{t} \mid R\right]$ (and $Y_{t}\left(q_{l}, q_{h}\right)$ conveys this decision).

The seller faces a tradeoff in $Y_{t}\left(q_{l}, q_{h}\right)$. The lower $Y_{t}\left(q_{l}, q_{h}\right)$ is, the better she will be able to perform the screening. However, a lower $Y_{t}\left(q_{l}, q_{h}\right)$ means that the seller may not be able to reap the benefits of the better screening, for it increases the ex-ante likelihood of the outside option being exercised. 


\subsection{Stationary Equilibrium}

In tandem with the mainstream of the literature, I will adopt the notion of stationary equilibrium: a sequential equilibrium satisfying the additional condition that for every history such that the current beliefs are a truncation of the priors, the informed party's current acceptance behavior is a function only of the current offer (see Asubel, Cramton and Deneckere, 2002).

In equilibrium, the buyer's acceptance decision must be optimal given the seller's offer behavior. Thus, the usual approach in Game Theory is to obtain an indifference condition that enables the strategy of the other player to be adjusted as a residual. In this particular model, it boils down to the relation between the offer $P\left(q_{l}, q_{h}\right)$ and its associated cutoff points $\left(q_{l}, q_{h}\right)$.

Proposition 2 The following equations represent the circumstances of the buyer's indifference condition toward the actions of the seller in the relevant twoperiod span:

$$
\begin{aligned}
\alpha\left(f(L)+q_{l}\right)+ & (1-\alpha)\left(f(H)+q_{l}\right)-P\left(q_{l}, q_{h}\right) \\
& =\delta_{b}\left(\frac{\left(f(L)+q_{l}\right)+\left(f(H)+q_{l}\right)}{2}-P\left(t\left(q_{l}, q_{h}\right)\right)\right) \gamma_{t}\left(q_{l}, q_{h}\right) \\
\alpha\left(f(H)+q_{h}\right)+ & (1-\alpha)\left(f(L)+q_{h}\right)-P\left(q_{l}, q_{h}\right) \\
& =\delta_{b}\left(\frac{\left(f(L)+q_{h}\right)+\left(f(H)+q_{h}\right)}{2}-P\left(t\left(q_{l}, q_{h}\right)\right)\right) \gamma_{t}\left(q_{l}, q_{h}\right)
\end{aligned}
$$

The quartet $\left\{P(), W_{s}(), t(), Y_{t}()\right\}$ determines a stationary equilibrium path in the following way. In the initial period, the seller selects (possibly randomly) an offer $P\left(q_{l}, q_{h}\right)$, for some $\left(q_{l}, q_{h}\right)$ belonging to the argmax of the Bellman's Equation of Proposition 1 with state variables $(1,1)$. Following this offer, all buyer types in the interval $\left[q_{l}, 1\right]$ accept if the signal was $s_{t}=l$, likewise, all buyer types in the interval $\left[q_{h}, 1\right]$ accept if the signal was $s_{t}=h$, rejection occurs otherwise. Since it is necessarily the case that $q_{l}<1$ and $q_{h}<1$, the equations above imply that following rejection of the offer $P\left(q_{l}, q_{h}\right)$ the buyer must face the offer $P\left(t\left(q_{l}, q_{h}\right)\right)$ should the seller decide to wait for another period, an event whose probability must have been correctly incorporated into the behavior of the buyer. The correspondence $t()$ denotes the argmax of the Bellman's Equation of Proposition 1 with state variables $\left(q_{l}^{+1}, q_{h}^{+1}\right)$. 


\subsection{Deadline Strategy}

A deadline strategy for the seller is such that upon reaching the belief that $\left(q_{l}, q_{h}\right)$ is below a certain level $\left(q_{l}^{*}, q_{h}^{*}\right), \Upsilon_{t}\left(q_{l}^{*}, q_{h}^{*}\right)=0$, but $\Upsilon_{t}\left(q_{l}, q_{h}\right)=1$ otherwise. Since a belief is formed by a number of rejections, possible one, it is simply a strategy that stipulates how long the game may last. This paper establishes that a solution for this game must involve a deadline strategy. In other words, the optimal payoff for the seller can only be attained through a deadline strategy. This result has economic meaning.

When the seller adopts a deadline strategy, she is, in effect, transferring the decision of when to exercise the option to the party that is best informed, which enables her to potentially reap the benefits of the optimal exercise. There is ample resonance in anecdotal evidence of this kind of behavior. For instance, a common practice in the trade of mineral rights is the Preemptive Rights Agreement, which legally enforces a term during which the buyer has exclusive rights to buy the asset, or in other words, such contract transfers the exercise decision to the buyer during a stipulated period of time.

The intuition of the following proof is simple. A credible mixed strategy requires the seller to be indifferent between exercising the option and moving to another period. However, the seller can never be indifferent, for if that is the case, her payoff can be improved. In such circumstance, if the seller exercises her outside option, she can increase the current period's payoff without compromising her total payoff, since the gains from more distant periods are "locked" in her outside option. The gist of this result is linked to Coase Conjecture (see Coase, 1972).

Theorem 1 A deadline strategy must be a part of any equilibrium in this game.

Having decided the optimal period to place her deadline, backwards induction dictates the remaining aspects of a stationary equilibrium. Therefore, a stationary equilibrium is entirely characterized by the number of rejections that leads to the exercise.

Theorem 2 The stationary equilibrium is unique. 


\subsection{Conclusion}

The absence of a centralized market allows negotiating players to consider opportunities outside the bargaining game. The bargaining process does not take place in a vacuum and is therefore correlated to these outside opportunities. This correlation is explored in this paper to enrich the asymmetric information structure, through the inclusion of a signal. The signal is private and conveys information regarding the correlation. However, this information is only meaningful to the bargaining game if it affects the payoff of the uninformed player, which it does through her outside option.

The paper contains two noteworthy results. First, if the relation between the buyer's payoff and its type is independent of the state of nature, then the inclusion of the signal doesn't affect a very important property, "Succesive Skimming". This property allows the model to be solved using both the standard method and concept of solution, dynamic programming and stationary equilibrium, respectively. Last, but not least, the functional form embodying the exercise of the outside option in a stationary equilibrium is identified. This function is necessarily binary, characterizing a equilibrium so common and intuitive that it even has a name in everyday language, "deadline".

Both results are connected to the existing literature. The first result can be seen as a slight generalization of the seminal result provided by Fudenberg, Levine and Tirole (1985). The second result provides a link between two important strains of the bargaining literature: bargaining with incomplete information and bargaining with deadlines. I have shown that an incomplete information setting can generate a deadline through the course of the game. This latter result has theoretical relevance and is, to the best of my knowledge, original. 


\section{A Reason The Secondary Market for Bank Loans Exists}

\subsection{Introduction}

The business of banking can be roughly divided into two models: originateto-hold and originate-to-distribute. Banks that make loans with the intention of holding them through maturity are said to be in the first category, while banks that do not are said to be in the second category. Many see the originate-to-distribute model as the villain of the subprime crisis, for it supposedly degrades credit quality by weakening banks' incentives to monitor the quality of the loans they write $^{2}$. If a bank does not expect to derive its profits from the repayment of loans, it may simply ignore the quality of its loans. Such reasoning assumes that monitoring loans is costly and that banks in the originate-to-distribute model have no incentives to incur in such cost.

Monitoring is usually assumed to be costly, but it is not always so. Most retail banks engage in relationship banking, providing a broad array of services, including checking and savings accounts. A bank that provides checking and savings accounts to a borrower that is part of its loan portfolio has access to a monitoring technology that has very low costs. Such monitoring technology poses a challenge for the adoption of the originate-to-distribute business model. Suppose, for instance, that a bank collects information about the quality of the credit it originated and adopts the originate-to-distribute business model, what would prevent it from cherry picking the best loans of its portfolio?

This paper argues that a capacity constraint on enforcing repayment enables banks with a costless monitoring technology to be sellers in the secondary market for loans. If there is a capacity constraint on enforcing repayment, borrowers are subject to strategic complementarity. Simply put, if a bank overwhelmed by defaults is incapable of enforcing repayment, then there is no incentive to repay a loan if too many defaults are expected, which may lead to borrower runs. Borrower runs are coordinated opportunistic defaults. Thus, this kind of default is

\footnotetext{
${ }^{2}$ The Economist, Special Report: International Banking, May 15th 2008.
} 
not related to loan quality, but to the capacity to enforce repayments. If a bank has no capacity to enforce repayments, then even a high quality portfolio may not confer enough resources to withstand a borrower run.

A bank threatened by a borrower run would be willing to sell its loan portfolio irrespective of any private information on the quality of the portfolio. However, unlike the quality of the loan portfolio, a bank's capacity to enforce repayment is assumed to be observable. Therefore, the inability to enforce repayment can be a credible commitment to ignore any acquired private information while selling the portfolio in the market for bank loans. This intuition underpins the result presented in this paper.

\subsection{Related Literature}

According to several authors - including Ramakrishnan and Thakor (1984), Diamond (1984), and Holmström and Tirole (1993) - banks' raison d'être is their comparative advantage in monitoring borrowers. Therefore, it is somewhat puzzling that there is a market for bank loans (see Pennacchi, 1988). Gorton and Pennacchi (1995) addressed the issue and proposed implicit guarantees and participation clauses as solutions to the misalignment of incentives that arises if banks are not at risk for failing to monitor their loan portfolio, which may happen if they sell it in the secondary market.

I investigate a related question: is there a market for bank loans when monitoring is costless but does not add value to the portfolio. Such setting would arguably describe a lender that engages in relationship banking but follows the originate-to-distribute model, for monitoring has very low costs in relationship banking while the originate-to-distribute model does not provide incentives for pre-contract monitoring, i.e. credit rationing (see Stiglitz and Weiss, 1981). It creates a different sort of misalignment of incentives, i.e. the adverse-selection described by Akerlof (1970), for only the bad loans would find their way to the secondary market.

Dang, Gorton and Holmstrom (2009) and Holmstrom (2015) discussed in general terms how the conclusions of Akerlof (1970) apply to the market of securities. They see debt-like securities as a mechanism that reduces incentive for private information production, thus minimizing asymmetric information and thus 
fostering liquidity. However, the production of private information is assumed to be costless in this paper.

The answer this paper develops is that there is a market for bank loans when monitoring is costless but does not add value to the portfolio if there is a capacity constraint on enforcing repayment. Following Carrasco and Salgado (2014), the level of liquidity determines the capacity to enforce loan repayment. However, I depart from the assumption that such cost can only be met with the bank's liquidity reserve, for there is the external source of liquidity of Acharya, Gromb and Yorulmazer (2012), a bank that does not originate credit but has surplus liquidity.

Therefore, the result this paper develops is also an answer to a different question: are borrower runs relevant if there is a secondary market for bank loans. Such claim would be a natural conjecture if, as in Carrasco and Salgado (2014), the level of liquidity determines the capacity to enforce loan repayment. If the originating bank can sell the loan to a bank with surplus liquidity, then a borrower run is an irrelevant possibility. I argue even though the existence of a secondary market for bank loans precludes borrower runs in equilibrium, borrower runs are not irrelevant. In the setting of this paper, the secondary market for bank loans owes its existence to the possibility of borrower runs.

\subsection{The Model}

The model has two dates $t=0,1$; two banks, bank $A$ and bank $B$; a continuum of entrepreneurs, universal risk neutrality and no discounting. Entrepreneurs are offered financing through a contract with bank A. Bank B may acquire the loans made by bank A before they mature. The structure follows Carrasco and Salgado (2014) closely, except that there is an uninformed bank B assumed to have enough liquidity to fund bank A's assets. Besides, I assume that banks are legally barred from publicly differentiating customers for posterior treatment upon default, a hypothesis that does not affect the main result.

At $t=0$, entrepreneurs are ex-ante identical, and endowed with a stochastic production technology which requires an initial investment $I>0$. They must borrow from a bank to develop the project, whose return $f(s)$ is i.i.d. across entrepreneurs, where $\partial f(s) / \partial s>0$. The probability distribution of $s$ is given by an absolutely continuous cumulative distribution function $H(s \mid \theta)$, with density 
$h(s \mid \theta)$ and support in a compact interval $[0, \bar{s}]$. The parameter $\theta \in[0, \bar{\theta}]$ conveys the quality of the portfolio, for $\partial H(s \mid \theta) / \partial \theta<0 \forall s$. At period $t=1$, entrepreneurs observe $s$ costlessly. However, a bank faces an audit cost $c(s)$ to unveil the returns of a project, where $\partial c(s) / \partial s \geq 0, \partial f(s) / \partial s \geq \partial c(s) / \partial s \forall s$. If the entrepreneur defaults on his loan, the bank imposes a constant cost of $c_{0}$ on $\operatorname{him}$

When signing a debt contract, the entrepreneur and the bank must agree on some points. The first is on the audit region $B([0, \bar{s}]) \subseteq[0, \bar{s}]$ that determines the circumstances in which observation costs are incurred. Let $B(s)$ be an indicator function taking value 1 at states in which seizure/audit takes place, and 0 otherwise. Another issue that must be agreed upon is how to share the proceeds of the project net of observation costs, given by the expression $f(s)-B(s) c(s)$.

A contract can be represented by an array $\left(R^{b}, R^{e}, B\right)$, where $R^{b}$ and $R^{e}$ are respectively the proceeds to the contracting bank and to the entrepreneur. A contract is incentive compatible if and only if:

(i) There exists a constant $D$ such that $R^{b}(s)=D$ if $B(s)=0$.

Condition (i) specifies a constant repayment schedule for the entrepreneur in the no-audit region.

$$
D \geq R^{b}(s)+c(s) \text { whenever } B(s)=1 .
$$

Condition (ii) guarantees that it is never in the entrepreneur's interest to report a non-audit state, when the true state specifies that an audit be realized.

As in Gale and Hellwig (1985), an optimal contract is defined as an incentive-compatible contract that maximizes the entrepreneur's expected utility subject to the banks' zero-profit condition. A standard debt contracts implies full expropriation in the audit region.

\section{Proposition 1. The optimal contract is a standard debt contract.}

The face value of debt $\mathrm{D}$ is chosen so as to guarantee that the bank does not have a profit in expectation and assumed to be bigger than $c_{0}$ (otherwise, no liquidity is needed to enforce repayment). Let $s^{D}$ be such that $f\left(s^{D}\right)=D$, then $D$ is implicitly defined by

$$
E_{\theta}\left(D\left(1-H\left(s^{D} \mid \theta\right)\right)+\int_{0}^{s^{D}}[f(s)-c(s)] h(s \mid \theta) d s\right)=I .
$$


Assumption 1. $D>f\left(s^{D}\right)-c\left(s^{D}\right)$.

Entrepreneurs are offered contracts with bank A, which may sell the contracts to bank B at $t=1$, after observing $\theta$ but before enforcing the terms of the contracts. If Bank $\mathrm{A}$ does not sell its loan portfolio to bank $\mathrm{B}$, it has an unknown liquidity need arising from the auditing of its non-performing loans and may constitute a liquidity reserve $E$.

I assume that the bank A adopts the following strategy regarding audits and seizures, which is common knowledge before contracting takes place:

$$
\text { only projects in default are seized; }
$$

(ii) the bank only seizes projects if it has the resources to audit them; and

(iii) the bank randomizes among projects in default when the budget constraint binds.

Such strategy may seem arbitrary, but rests on the assumption that bank faces a legal restriction on ex-ante public separation of the entrepreneurs into groups subject to different treatment upon default. Besides, setting public priority lists for contract enforcement may even be a bad commercial strategy, for customers may shun the risk of being placed in such a list. However, how bank A proceeds in terms of audits/seizures is not crucial for the main result of this paper.

Proposition 2. When confronted with a probability $p$ of audit and a debt level $D$, there is a cutoff state $s^{*}$ such that entrepreneur $i$ defaults if and only if $s_{i} \leq s^{*}$.

Definition 1. In case bank $A$ does not sell its portfolio, a repayment equilibrium is given by a ordered pair $\left(s^{*}, p\right)$ such that:

(i) $\quad p\left(E, s^{*}, \theta\right)=\min \left(\frac{E+D\left(1-H\left(s^{*} \mid \theta\right)\right)}{\int_{0}^{s^{*}} c(s) h(s \mid \theta) d s}, 1\right)$;

(ii) entrepreneur $i$ defaults if and only if $s_{i} \leq s^{*}$.

Definition 2. A borrower run is a repayment equilibrium in which $s^{*}>s^{D}$.

Assumption 2. Bank $A$ only recovers a proportion $p\left(E, s^{*}, \theta\right)$ of the value of the debts in default.

In equilibrium, bank B only buys a loan portfolio if it does not expect to lose money by paying $\rho \in[0,1)$ on the dollar. However, as bank A observes the realization of $\theta$ before selling its portfolio, a mechanism like Akerlof's (1970) is at play.

Theorem. The secondary market for bank loans only exists if borrower runs are expected. 
Corollary. The secondary market for bank loans only exists if $E<$ $\int_{0}^{\bar{s}} c(s) h(s \mid \bar{\theta}) d s$.

\subsection{Conclusion}

This paper analyzes the role the prospect of borrower runs plays when relationship banking is adopted simultaneously to the originate-to-distribute business model. Such bank would be able to monitor its clients very efficiently, perhaps too efficiently for it to be able to sell its portfolio in a secondary market for bank loans. Besides, it is assumed that originate-to-distribute business model does not provide any incentive for credit rationing, thus there is no pre-contract monitoring. In this setting, it is shown that no transaction would take place in the market for bank loans in the absence of the expectation of borrower runs. However, if the bank's capacity to enforce repayment is determined by its level of liquidity, then a limited liquidity reserve and the expectation of borrower runs imply that all realizations of the quality parameter of the loan portfolio are taken to the secondary market. Therefore, the expectation of borrower runs enables relationship banking in conjunction to the originate-to-distribute business model. This result is interesting for it connects the originate-to-distribute business model to liquidity risk in a fundamental way, for there can be no originate-to-distribute business model in the absence of liquidity risk. 


\section{References}

Acharya, V., Gromb, D., Yorulmazer, T. (2012). Imperfect competition in the interbank market for liquidity as a rationale for central banking. American Economic Journal: Macroeconomics 4(2): 184-217.

Akerlof, G. (1970). The Market for "Lemons": Quality Uncertainty and the Market Mechanism. The Quarterly Journal of Economics 84(3): 488-500.

Asubel, Lawrence, Cramton, Peter, and Deneckere, Raymond (2002). Bargaining with incomplete information. Handbook of Game Theory, vol. 3, Aumann J., Hart, S. (Eds.), Elsevier Science Publishers B.V., Greenwich, Connecticut: 1897-1945.

Avery, Christopher and Zemsky, Peter (1994). Option Values and Bargaining Delays. Games and Economic Behavior 7: 139-153.

Carrasco, V., Salgado, P. (2014). Coordinated strategic defaults and financial fragility in a costly state verification model. Journal of Financial Intermediation 23: 129-139.

Coase, Ronald (1972). Durability and Monopoly. Journal of Law and Economics, vol. 15(1): 143-49.

Dang, Tri Vi, Gorton, Gary and Holmstrom, Bengt (2009). Opacity and the Optimality of Debt for Liquidity Provision. Working Paper.

Deneckere, Raymond and Meng-Yu, Liang (2006). Bargaining with Interdependent Values. Econometrica 74 (5): 1309-1364,

Diamond, D. (1984). Financial Intermediation and Delegated Monitoring. Review of Economic Studies 51 (3): 393-414.

Fershtman, Chaim and Seidmann, Daniel (1993). Deadline Effects and Inefficient Delay in Bargaining with Endogenous Commitment. Journal of Economic Theory 60: 306-321.

Fuchs, William and Skrypacz, Andrzej (2010). Bargaining with Arrival of New Traders. American Economic Review 100 (3): 802-836. 
Fundenberg, Drew, Levine, David and Tirole, Jean (1985). Infinite-Horizon Models of Bargaining with One-Sided Incomplete Information. Game Theoretic Models of Bargaining, Alvin Roth (ed), Cambridge, England.

Fundenberg, Drew, Levine, David and Tirole, Jean (1987). Incomplete Information Bargaining with Outside Opportunities. The Quarterly Journal of Economics 102 (1): 37-50.

Gale, D., Hellwig, M. (1985). Incentive-compatible debt contracts: the oneperiod problem. Review of Economic Studies 52 (4): 647-663.

Gorton, G., and Pennacchi, G. (1995). Banks and Loan Sales: Marketing Nonmarketable Assets. Journal of Monetary Economics 35 (3): 389-411.

Hanazono, Makoto and Watanabe, Yasutora (2012). Information Aggregation in Bargaining. Working Paper.

Holmström, B., and Tirole, J. (1993). Market Liquidity and Performance Monitoring. Journal of Political Economy 101 (4): 678-709.

Holmström, B. (2015). Understanding the role of debt in the financial system. BIS Working Paper 479.

Mauleon, Ana and Vannetelbosch, Vincent (2004). Bargaining with endogenous deadlines. Journal of Economic Behavior \& Organization 54: 321335.

Merlo, Antonio and Wilson, Charles (1995). Stochastic Model of Sequential Bargaining with Complete Information. Econometrica 63 (2): 371-399.

Merlo, Antonio and Wilson, Charles (1998). Efficient Delays in a Stochastic Model of Bargaining. Economic Theory 11 (1): 39-55.

Pennacchi, G. (1988). Loan Sales and the Cost of Bank Capital. Journal of Finance 43 (2): 375-396.

Ramakrishnan, R., and Thakor, A. (1984). Information Reliability and a Theory of Financial Intermediation. Review of Economic Studies 51 (3): 415-32.

Rubinstein, Ariel (1982). Perfect Equilibrium in a Bargaining Model. Econometrica 50 (1): 97-109.

Stiglitz, J., and Weiss, A. (1981). Credit Rationing in Markets with Imperfect Information. The American Economic Review 71 (3): 393-410. 


\section{Appendix}

\subsection{First Essay}

\section{Lemma 1 (proof)}

The buyer of type $q_{l}$ accepts the offer $P\left(h_{n}, q_{l}, q_{h}\right)$ when his private signal is $l$ and the history of the game is $h_{n}$, thus:

$$
\alpha\left(f(L)+q_{l}\right)+(1-\alpha)\left(f(H)+q_{l}\right)-P\left(h_{n}, q_{l}, q_{h}\right) \geq \delta_{b} W_{b}\left(q_{l}, h_{n+1}, l\right)
$$

where $W_{b}\left(q_{l}, h_{n+1}, l\right)$ is the value of the continuation of the game for a buyer whose type is $q_{l}$ - when the history of the game is $h_{n+1}$, including $P\left(h_{n}, q_{l}, q_{h}\right)$, and his current signal is $l$.

Consider now a buyer of a type greater than $q_{l}, q_{l}^{\prime}$. The buyer of type $q_{l}$ can always follow the optimal strategy for a buyer of type $q_{l}^{\prime}$, that is, accept only in the cases such buyer would have accepted. Given that $W_{b}$ designates the maximum expected payoff of all possible strategies, we have:

$$
\begin{aligned}
W_{b}\left(q_{l}^{\prime}, h_{n+1}, l\right) & -W_{b}\left(q_{l}, h_{n+1}, l\right) \\
& \leq \sum_{i=1}^{\infty} \delta_{b}^{i}\left(0 . 5 \rho _ { n + 1 + i } ( q _ { l } ^ { \prime } , h _ { n + 1 } , l ) \left(\alpha\left(\left(f(L)+q_{l}^{\prime}\right)-\left(f(L)+q_{l}\right)\right)\right.\right. \\
& \left.+(1-\alpha)\left(\left(f(H)+q_{l}^{\prime}\right)-\left(f(H)+q_{l}\right)\right)\right) \\
& +0.5 \rho_{n+1+i}\left(q_{l}^{\prime}, h_{n+1}, l\right)\left(\alpha\left(\left(f(H)+q_{l}^{\prime}\right)-\left(f(H)+q_{l}\right)\right)\right. \\
& \left.\left.+(1-\alpha)\left(\left(f(L)+q_{l}^{\prime}\right)-\left(f(L)+q_{l}\right)\right)\right)\right)
\end{aligned}
$$

where $i$ is the index of time and $\rho_{n+1+i}\left(q_{l}^{\prime}, h_{n+1}, l\right)$ is defined as the probability of agreement at period $n+1+i$ when the buyer adopts the strategy that is optimal for the type $q_{l}^{\prime}$, conditional on the history $h_{n+1}$ and the current signal being $l$. As with any probability, $\sum_{i=1}^{\infty} \rho_{n+1+i}\left(q_{l}^{\prime}, h_{n+1}, l\right) \leq 1$, thus: 


$$
\begin{aligned}
\sum_{i=1}^{\infty} \delta_{b}^{i}\left(0 . 5 \rho _ { n + 1 + i } ( q _ { l } ^ { \prime } , h _ { n + 1 } , l ) \left(\alpha\left(\left(f(L)+q_{l}^{\prime}\right)-\left(f(L)+q_{l}\right)\right)\right.\right. \\
\left.+(1-\alpha)\left(\left(f(H)+q_{l}^{\prime}\right)-\left(f(H)+q_{l}\right)\right)\right) \\
+0.5 \rho_{n+1+i}\left(q_{l}^{\prime}, h_{n+1}, l\right)\left(\alpha\left(\left(f(H)+q_{l}^{\prime}\right)-\left(f(H)+q_{l}\right)\right)\right. \\
\left.\left.+(1-\alpha)\left(\left(f(L)+q_{l}^{\prime}\right)-\left(f(L)+q_{l}\right)\right)\right)\right) \leq q_{l}^{\prime}-q_{l} \\
=\alpha\left(\left(f(L)+q_{l}^{\prime}\right)-\left(f(L)+q_{l}\right)\right) \\
+(1-\alpha)\left(\left(f(H)+q_{l}^{\prime}\right)-\left(f(H)+q_{l}\right)\right) \\
=\alpha\left(\left(f(H)+q_{l}^{\prime}\right)-\left(f(H)+q_{l}\right)\right) \\
+(1-\alpha)\left(\left(f(L)+q_{l}^{\prime}\right)-\left(f(L)+q_{l}\right)\right)
\end{aligned}
$$

which implies that payoff gains associated with greater types are concentrated on the current period, thus, the offer $P\left(h_{n}, q_{l}, q_{h}\right)$ is accepted by any buyer whose type is greater than $q_{l}$ - when his private signal is $l$ and the history of the game is $h_{n}$. An identical argument establishes that the offer $P\left(h_{n}, q_{l}, q_{h}\right)$ is accepted by any buyer whose type is greater than $q_{h}$ - when his private signal is $h$ and the history of the game is $h_{n}$, which concludes the proof.

\section{Lemma 2 (proof)}

Ignore the history of the game but for the last offer, and let $P\left(q_{l}^{\prime}, q_{h}^{\prime}\right)$ denote an offer that would be accepted by the $\left[q_{l}^{\prime}, 1\right]$ types if the buyer's signal is $l$ and $\left[q_{l}^{\prime}, 1\right]$ otherwise. As in Proposition $1, R$ stands for a rejection of such offer.

$$
\begin{gathered}
\operatorname{Pr}\left(s_{t}=l \mid R\right)=\frac{\operatorname{Pr}\left(R \mid s_{t}=l\right) \operatorname{Pr}\left(s_{t}=l\right)}{\operatorname{Pr}\left(R \mid s_{t}=l\right) \operatorname{Pr}\left(s_{t}=l\right)+\operatorname{Pr}\left(R \mid s_{t}=h\right) \operatorname{Pr}\left(s_{t}=h\right)}=\frac{\frac{q_{l}^{\prime}}{q_{l}^{0}}}{\frac{q_{l}^{\prime}}{q_{l}^{0}}+\frac{q_{h}^{\prime}}{q_{h}^{0}}} \\
\rightarrow \operatorname{Pr}\left(s_{t}=h \mid R\right)=\frac{\frac{q_{h}^{\prime}}{q_{h}^{0}}}{\frac{q_{l}^{\prime}}{q_{l}^{0}}+\frac{q_{h}^{\prime}}{q_{h}^{0}}}
\end{gathered}
$$

There is a relationship between $q_{l}$ and $q_{h}$ embedded in $f\left(Z_{t}\right)+q$. In particular, the fact that the underlying process $Z_{t}$ follows an i.i.d. random variable implies that the current signal does not affect the expected payoff of a rejection, thus, $f(L)+q_{l}=f(H)+q_{h}$. However, in order to simplify the notation and generalize the result, I will simply state that the seller would be able to infer 
$q_{l}\left(q_{h}\right)$ had she known $q_{h}\left(q_{l}\right)$. The pair of functions $\left(\varphi_{l}\left(q_{h}\right), \varphi_{h}\left(q_{l}\right)\right)$ embodies this statement.

$$
\begin{gathered}
q_{l}^{1}=\operatorname{Pr}\left(s_{t}=l \mid R\right) q_{l}^{\prime}+\operatorname{Pr}\left(s_{t}=h \mid R\right) \varphi_{h}\left(q_{l}^{\prime}\right)=\frac{\frac{q_{l}^{\prime}}{q_{l}^{0}} q_{l}^{\prime}+\frac{q_{h}^{\prime}}{q_{h}^{0}} \varphi_{h}\left(q_{l}^{\prime}\right)}{\frac{q_{l}^{\prime}}{q_{l}^{0}}+\frac{q_{h}^{\prime}}{q_{h}^{0}}} \\
q_{h}^{1}=\operatorname{Pr}\left(s_{t}=h \mid R\right) q_{h}^{\prime}+\operatorname{Pr}\left(s_{t}=l \mid R\right) \varphi_{h}\left(q_{h}^{\prime}\right)=\frac{\frac{q_{l}^{\prime}}{q_{l}^{0}} \varphi_{h}\left(q_{h}^{\prime}\right)+\frac{q_{h}^{\prime}}{q_{h}^{0}} q_{h}^{\prime}}{\frac{q_{l}^{\prime}}{q_{l}^{0}}+\frac{q_{h}^{\prime}}{q_{h}^{0}}}
\end{gathered}
$$

Given the prior, each successive rejection leads unambiguously to the new belief, which concludes the proof.

Theorem 1 (proof)

Consider an arbitrary equilibrium $\left\{P^{*}(), W_{s}^{*}(), t^{*}(), Y_{t}^{*}()\right\}$. Suppose that at an arbitrary point $\left(q_{l}^{+}, q_{h}^{+}\right)$, the equilibrium prescribes $1>\gamma_{t}^{*}\left(q_{l}^{+}, q_{h}^{+}\right)>0$. It follows from a well-known result in Game Theory that the seller must indifferent between exercising her outside option and moving to another period:

$$
E\left[Z_{t} \mid R\right]=\delta_{s} W_{S}\left(q_{l}^{+1}, q_{h}^{+1}\right)
$$

As the seller is indifferent, the binding constraint is the buyer's belief.

$$
\begin{aligned}
\alpha\left(f(L)+q_{l}^{+}\right) & +(1-\alpha)\left(f(H)+q_{l}^{+}\right) \\
& -\delta_{b}\left(\frac{\left(f(L)+q_{l}^{+}\right)+\left(f(H)+q_{l}^{+}\right)}{2}-P^{*}\left(t^{*}\left(q_{l}^{+}, q_{h}^{+}\right)\right)\right) \gamma_{t}^{*}\left(q_{l}, q_{h}\right) \\
& =P^{*}\left(q_{l}^{+}, q_{h}^{+}\right) \\
\alpha\left(f(H)+q_{h}^{+}\right) & +(1-\alpha)\left(f(L)+q_{h}^{+}\right) \\
& -\delta_{b}\left(\frac{\left(f(L)+q_{h}^{+}\right)+\left(f(H)+q_{h}^{+}\right)}{2}-P^{*}\left(t^{*}\left(q_{l}^{+}, q_{h}^{+}\right)\right)\right) Y_{t}^{*}\left(q_{l}^{+}, q_{h}^{+}\right) \\
& =P^{*}\left(q_{l}^{+}, q_{h}^{+}\right)
\end{aligned}
$$

However, the fact that the seller is indifferent implies that the current offer could be improved to $P^{* *}\left(q_{l}^{+}, q_{h}^{+}\right)$, yet remain credible (i.e. the probability of acceptance would remain the same) while the expected payoff from the continuation of the game would remain unchanged (i.e. $E\left[Z_{t} \mid R\right]$ ).

$$
\begin{aligned}
& \alpha\left(f(L)+q_{l}^{+}\right)+(1-\alpha)\left(f(H)+q_{l}^{+}\right)=P^{* *}\left(q_{l}^{+}, q_{h}^{+}\right) \\
& \alpha\left(f(H)+q_{h}^{+}\right)+(1-\alpha)\left(f(L)+q_{h}^{+}\right)=P^{* *}\left(q_{l}^{+}, q_{h}^{+}\right)
\end{aligned}
$$


Therefore, if the optimal payoff for the seller prescribes a mixed strategy, the same payoff can be attained through a deadline strategy. Remarkably, the only case in which the seller is not strictly better off by doing so is if:

$$
\begin{aligned}
& \frac{\left(f(L)+q_{l}^{+}\right)+\left(f(H)+q_{l}^{+}\right)}{2}=P^{*}\left(t^{*}\left(q_{l}^{+}, q_{h}^{+}\right)\right) \\
& \frac{\left(f(L)+q_{h}^{+}\right)+\left(f(H)+q_{h}^{+}\right)}{2}=P^{*}\left(t^{*}\left(q_{l}^{+}, q_{h}^{+}\right)\right)
\end{aligned}
$$

The correspondence $t^{*}\left(q_{l}, q_{h}\right)$ reflects two things: the change of beliefs and the subsequent optimizing behavior. The change of beliefs, as previously discussed, is extraneous in the sense that it is not subject to any strategic consideration. That the optimizing behavior on such beliefs could fall on such specific value could only be called a coincidence.

Besides, it implies the unnatural conclusion that $q_{l}^{+}$must be equal to $q_{h}^{+}$(i.e. the signal does not affect whether the buyer accepts $P^{*}\left(q_{l}^{+}, q_{h}^{+}\right)$or not). If $f(L) \neq f(H)$, as I have implicitly assumed, this particular case amounts to a contradiction and can be safely ruled out. Thus, the stationary equilibrium can only be achieved through a deadline strategy, concluding the proof.

\section{Theorem 2 (proof)}

Consider two stationary equilibra that impose the same deadline $Y_{t}^{1}\left(q_{l}, q_{h}\right)=Y_{t}^{2}\left(q_{l}, q_{h}\right) \forall\left(q_{l}, q_{h}\right)$. If $Y_{t}^{i}\left(q_{l}^{*}, q_{h}^{*}\right)=0$, then following a rejection of $P^{i}\left(q_{l}^{*}, q_{h}^{*}\right)$, the seller exercises her option.

$$
\begin{aligned}
& \alpha\left(f(L)+q_{l}^{*}\right)+(1-\alpha)\left(f(H)+q_{l}^{*}\right)=P^{1}\left(q_{l}^{*}, q_{h}^{*}\right)=P^{2}\left(q_{l}^{*}, q_{h}^{*}\right) \\
& \alpha\left(f(H)+q_{h}^{*}\right)+(1-\alpha)\left(f(L)+q_{h}^{*}\right)=P^{1}\left(q_{l}^{*}, q_{h}^{*}\right)=P^{2}\left(q_{l}^{*}, q_{h}^{*}\right)
\end{aligned}
$$

Therefore, the final offer must be the same. Now, assume the alternative, $Y_{t}^{i}\left(q_{l}^{*}, q_{h}^{*}\right)=1$. Define $n$ as the number of rejections that separate this particular offer from the one that induces the exercise of the seller's option. The reason I can express the trajectory of her beliefs in terms of the number of rejections is due to Lemma 2 . The argument then proceeds by induction.

The final offer is denoted by $P_{0}$, the preceding offer $P_{1}\left(q_{l}^{*}, q_{h}^{*}\right)$ is obtained as follows:

$$
\begin{aligned}
\alpha\left(f(L)+q_{l}^{*}\right)+ & (1-\alpha)\left(f(H)+q_{l}^{*}\right)-\delta_{b}\left(\frac{\left(f(L)+q_{l}^{*}\right)+\left(f(H)+q_{l}^{*}\right)}{2}\right)+\delta_{b} P_{0} \\
& =P_{1}\left(q_{l}^{*}, q_{h}^{*}\right)
\end{aligned}
$$




$$
\begin{aligned}
\alpha\left(f(H)+q_{h}^{*}\right) & +(1-\alpha)\left(f(L)+q_{h}^{*}\right)-\delta_{b}\left(\frac{\left(f(L)+q_{h}^{*}\right)+\left(f(H)+q_{h}^{*}\right)}{2}\right) \\
& +\delta_{b} P_{0}=P_{1}\left(q_{l}^{*}, q_{h}^{*}\right)
\end{aligned}
$$

Clearly, any offer is unambiguously determined by its posterior offer, thus, the induction argument is valid. As it implies $P_{1}\left(q_{l}, q_{h}\right)=P_{2}\left(q_{l}, q_{h}\right) \forall\left(q_{l}, q_{h}\right)$, the same acceptance behavior ensues, implying that the equilibria which possess the same deadline strategy are equivalent.

The uniqueness of the equilibrium follows from the optimizing behavior of the seller and the binary structure of $Y_{t}\left(q_{l}, q_{h}\right)$, as established in Theorem 1 . Suppose the existence of two distinct deadlines, $Y_{t}^{1}\left(q_{l}, q_{h}\right) \neq Y_{t}^{2}\left(q_{l}, q_{h}\right)$ for some $\left(q_{l}, q_{h}\right)$. Thus, without loss of generality, $Y_{t}^{1}\left(q_{l}^{*}, q_{h}^{*}\right)=1$ while $Y_{t}^{2}\left(q_{l}^{*}, q_{h}^{*}\right)=0$, which implies the following:

$$
\delta_{s} W_{s}^{2}\left(q_{l}^{*+1}, q_{h}^{*+}\right)>E\left[Z_{t} \mid R\right]>\delta_{s} W_{s}^{1}\left(q_{l}^{*+1}, q_{h}^{*+}\right)
$$

which is a contradiction because $W_{s}^{2}\left(q_{l}^{*+1}, q_{h}^{*+}\right)>W_{s}^{1}\left(q_{l}^{*+1}, q_{h}^{*+}\right)$ violates the optimum condition embedded in $W_{S}$.

\subsection{Second Essay}

Theorem. (proof)

In equilibrium,

$$
\rho D=E_{\theta}(B(\theta) \mid I(E, \theta)<\rho D) .
$$

Where:

$$
\begin{gathered}
B(\theta) \equiv D\left(1-H\left(s^{D} \mid \theta\right)\right)+\int_{0}^{s^{D}}[f(s)-c(s)] h(s \mid \theta) d s, \\
I(E, \theta) \equiv D\left(1-H\left(s^{*} \mid \theta\right)\right)+p\left(E, s^{*}, \theta\right) \int_{0}^{s^{*}}[f(s)-c(s)] h(s \mid \theta) d s .
\end{gathered}
$$

Besides, the threshold $s^{*}$ is implicitly defined by:

$$
\begin{gathered}
\left(1-p\left(E, s^{*}, \theta\right)\right) f\left(s^{*}\right)-c_{0}=f\left(s^{*}\right)-D \leftrightarrow p\left(E, s^{*}, \theta\right) f\left(s^{*}\right)=D-c_{0}, \\
f\left(s^{D}\right)=D-c_{0}, \\
p\left(E, s^{*}, \theta\right)=\min \left(\frac{E+D\left(1-H\left(s^{*} \mid \theta\right)\right)}{\int_{0}^{s^{*}} c(s) h(s \mid \theta) d s}, 1\right) .
\end{gathered}
$$


Assuming $\left(s^{D}, 0\right)$ is the repayment equilibrium, consider the existence of an equilibrium in which bank A sells portfolios such that $\theta \in\left[0, \theta^{*}\right], \theta^{*} \neq 0$. In this case, the equilibrium would imply:

$$
\rho D=E_{\theta \in\left[0, \theta^{*}\right]}(B(\theta)) .
$$

However, $B^{\prime}(\theta)>0$ :

$$
\begin{gathered}
B^{\prime}(\theta)=-D\left(\frac{\partial H\left(s^{D} \mid \theta\right)}{\partial \theta}\right)+\int_{0}^{s^{D}}[f(s)-c(s)] \frac{\partial h(s \mid \theta)}{\partial \theta} d s \\
=\left(f\left(s^{D}\right)-c\left(s^{D}\right)-D\right)\left(\frac{\partial H\left(s^{D} \mid \theta\right)}{\partial \theta}\right)-\int_{0}^{s^{D}}\left[f^{\prime}(s)-c^{\prime}(s)\right] \frac{\partial H(s \mid \theta)}{\partial \theta} d s \\
>0
\end{gathered}
$$

Which means that there is a $\theta^{* *} \in\left[0, \theta^{*}\right]$ such that:

$$
I\left(E, \theta^{* *}\right)=B\left(\theta^{* *}\right)>\rho D=E_{\theta \in\left[0, \theta^{*}\right]}(B(\theta))
$$

Thus, bank A does not find it optimal to sell its portfolio when $\theta \in\left[\theta^{* *}, \theta^{*}\right]$, a contradiction.

This reasoning, which is Akerlof's (1970) insight, leads to the conclusion that $\rho D=B(0)$ is the only possible equilibrium when $\left(s^{D}, 0\right)$ is the repayment equilibrium. Thus, the market existence is a zero probability event.

It remains to be shown that there is at least one repayment equilibrium in which the secondary market for bank loans exists.

Assuming $(\bar{s}, 0)$ is the repayment equilibrium,

$$
\rho D=E_{\theta}(B(\theta) \mid I(E, \theta)<\rho D)=E_{\theta}(B(\theta) \mid 0<\rho D)=E_{\theta}(B(\theta)) .
$$

Which holds as an equilibrium.

Corollary. (proof)

$$
E>\int_{0}^{\bar{s}} c(s) h(s \mid \bar{\theta}) d s \rightarrow p\left(E, s^{*}, \theta\right)=1 \forall \theta
$$

